\title{
A Descriptive Study of Clients' Perspective on Psychoeducation in a Nigerian Tertiary Hospital
}

Takai MG and Aghukwa Nkereuwem Chikaodiri*

Department of Psychiatry, Aminu Kano Teaching Hospital, Kano, Nigeria

\begin{abstract}
Objective: Giving information to patients and their relations about the illness has a proven advantage towards sustaining an improved mental health in the patients. This study set to know if the patients that attended the mental health services in a tertiary hospital in Nigeria received psychoeducation during formal clinic consultations.

Method: A cross sectional descriptive study that interviewed randomly selected 336 patients and their relatives who have been utilizing the hospital's Specialty Out-patient Clinic facility. A pretested interviewer administered questionnaire was designed for this study that sort to know if during clinic consultations, the respondents were given basic information about the illness, the drug treatment and how to cope with the stress and stigma that comes with mental illness.

Result: Schizophrenia disorder was the predominant illness among the respondents and despite an average of about 7 years of coming for routine checkups at the clinic, most of them were not given information on the basic issues about the illness. The majority of the respondents were not told how and what the drugs do. Despite more than half of them have been told the names and how to use their medications, most were not informed about the likely side effects of the drugs. More than ninety percent of the respondents were not informed about stress coping and managing with the stigma associated with the illness.
\end{abstract}

Conclusion: The data suggest that the patients and their relations do not receive enough psychoeducational interventions during routine clinic visitations.

Keywords: Patients and their relations; Psychoeducation; Treatment

\section{Introduction}

Psychoeducation is a professional talking form of treatment that applies psychotherapy and education in the care of people with mental illness which use may be undermined in normal clinical settings especially in developing countries. Psychoeducation is a concept that is not only applied to mental health conditions such as schizophrenia, depression, anxiety, etcetera, but to such physical illnesses as cancer, hypertension, diabetes, HIV and others. It reflects a paradigm shift from the traditional medical model to treat pathology and dysfunction to a more holistic approach with health, collaboration and patient/relations empowerment at the core of the model [1]. One ponders if there is an overlook of this aspect of patient care since it does not involve the use of drugs when caring for them by health professionals especially in underdeveloped/developing countries such as Nigeria. The study reports on the effectiveness of 9 months family psychoeducational intervention in long term treatment outcome measures in patients with schizophrenia caused the backing by policy makers and organized groups in the United States, the recommendation for its inclusion in the clinical management of such patients [2]. Weekly group psychoeducation alongside standard medical care over 21 per 90 minute sessions helps patients with bipolar affective disorder and their family members in the long term management of their problem $[3,4]$. Depression, which is about the third seen cases in primary care clinic consultations, is often better managed by a combination of medication and several types of psychotherapy like Cognitive Behavioural Therapy (CBT) and Interpersonal Therapy (IPT) at about 90 minutes 12 weekly sessions [5]. Brief inexpensive psychoeducational intervention, especially in busy clinics has helped reduce relapses in patients with depression, anxiety related problems, and other psychological distresses. In the long term, behavioural, cognitive or a combination of both, Cognitive Behavioural Therapy (CBT), in various models has additive effects with drugs in the treatment of patients with anxiety disorders [6]. Psychoeducational interventions do impact positive knowledge about epilepsy, reduce misinformation and misconceptions about it, and teach people with epilepsy and their families on better ways of coping with the illness [7]. Donley first used the term psychoeducation in 1911 in an article titled "Psychotherapy and reeducation" but Tomlinson 30 years later introduced this to medical literature and by 1980 Anderson in the course of finding improved care for people with schizophrenia popularized and developed psychoeducation into its current form [8]. Because a diverse group of mental health problems comes with life altering positions, the need to educate the patients and their families/carers' as well as their active participation in the care is in the right context. Over 30 randomized clinical trials showed that family psychoeducation programs reduce relapse, improve symptomatic recovery, and enhance psychosocial and family outcomes in persons with schizophrenia and bipolar disorders [9]. These advantages have led to the American Psychiatric Association's inclusion of psychoeducation in the treatment guidelines for patients with schizophrenia, and the family oriented type in the routine management of patients in psychiatric settings by the Substance Abuse and Mental Health Services Administration [10].

*Corresponding author: Aghukwa Nkereuwem Chikaodiri, Department of Psychiatry, Aminu Kano Teaching Hospital, Kano, Nigeria, Tel: 08061360853. E-mail: drchikan@yahoo.co.uk

Received March 16, 2015; Accepted April 21, 2015; Published April 28, 2015

Citation: Takai MG, Chikaodiri AN (2015) A Descriptive Study of Clients' Perspective on Psychoeducation in a Nigerian Tertiary Hospital. J Psychiatry 18: 282 doi: http://dx.doi.org/10.4172/2378-5756.1000282

Copyright: @ 2015 Takai MG, et al. This is an open-access article distributed under the terms of the Creative Commons Attribution License, which permits unrestricted use, distribution, and reproduction in any medium, provided the original author and source are credited 
Agara and Onibi claimed that group psychoeducation among Nigerian psychiatric patients improves keeping to outpatient appointments in both the young and old among them [11]. Psychoeducation has its root in behavioural therapy but could involve some aspects of clientcentered therapy in either the individual or group methods of therapy. This aspect of psychotherapeutic psychoeducation usually lasts between 45 minutes to 1 hour per session and may involve professionals such as doctors, nurses, social workers and psychologists. The sole aim of this is to educate the patients and their relations about the illness, enable them on better ways of coping, on personal handling and support to their relations so afflicted [8].

Psychoeducation is an important mental health intervention that improves patient care, and previous interventional studies in Nigeria and Uganda found that it improved patients' compliance to treatment. But these studies did not assess the patients and their relations opinion on the application of psychoeducation in routine clinical mental health consultations. This study was based on the hypothesis that half of the respondents should and the other half should not receive appropriate psychoeducational interventions during treatment $[11,12]$. The primary purpose of the study, which was the first known to the author in the present place of the survey, was to know if the patients that attended the mental health services at the Aminu Kano Teaching Hospital routinely received psychoeducation in their course of treatment. The second goal was to know if some kinds of information are given to the patients and their relations during treatment, thirdly to find out if they have been engaged in any form of psychotherapeutic intervention while receiving treatment. The outcome of the study should guide the mental health professionals and health policy makers in planning a better and improved service delivery to people with mental health issues.

\section{Methods}

\section{Site}

This was a cross-sectional descriptive study. The study was conducted at the Aminu Kano Teaching Hospital's Outpatients Specialty Clinic.

Participants for the study: The subjects for the study came from the population of patients that came for psychiatric consultation at the specialty clinic within the period of study. First time clinic attenders, those who could not give a good account of the illness, and accompanying relations who did not have a good grasp about the patient's problems were not part of the assessment. The sample size was calculated using the sample size for a finite population formulae $\mathrm{SS}=\mathrm{SS} / 1+(\mathrm{SS}-1 / \mathrm{Pop})(\mathrm{SS}=$ sample size, $\mathrm{Pop}=$ population $)$. This gave a sample size of 310 and this increased to 350 to give room for attritions.

Method of data collection: Dater was collected with a questionnaire that was designed for this study which was pretested before use. The clients' opinion about psychoeducation questionnaire contained four sections, questions on the patients Sociodemographic characteristics covered the first section. Sections B-D each contain six questions, the second section wished to know if the patients and their relations were given basic information about the illness with an internal consistency of 0.79 as estimated with the Cronbach's alpha test of reliability. The third section which had six questions about knowledge on the drugs taken by the patients had a Cronbach's alpha internal consistency of 0.76. And the last section which asked about perceived stigma and coping with the stress of illness by both the patients and the relations, caring for them also had a Cronbach's alpha of 0.79. The details of the questions are shown in the appended questionnaire (Appendix 1).
Method of data collection: A proportionate number of the subjects were selected from the clinic attenders on each of the days of consultation in every week and the selected subjects were interviewed during the consultation with the consultant psychiatrist and two trainee psychiatrists. The patients were primarily interviewed with the accompanying relations corroborating with the information from the patient. All the consenting patients signed the consent form before willingly responding to the questionnaire.

\section{Data analysis}

Data was analyzed with SPSS version 17. Descriptive information was presented with simple frequency tables while summarizing categorical and numerical data with absolute numbers, percentages and means where applicable. The chi-square test of significance at 0.05 value, was used to compare the dichotomous responses.

\section{Ethics}

Ethical approval for the research was granted by The Aminu Kano Teaching Hospital's ethical committee. The participants signed an approved consent form before every interview.

\section{Results}

A total of 336 responses from the estimated 350 sample size of the study, been ninety-six percent of the earlier, was collated and analyzed. The means of the respondents' age and the length of time of coming to receive treatment at the hospital's mental health facility were, 37.1 years \pm 13.96 and 6.65 years \pm 5.82 respectively. Among the respondents, there were $147(43.8 \%)$ males and 189 (56.2\%) females of which 137 (40.8\%) were not married, 179 (53.2\%) were married and $20(6.0 \%)$ were either divorced or separated from their spouses. One hundred and ninety five (58\%) of the respondents had no gainful employment, 95 (28.3\%) were public servants and 46 (13.7\%) had their private businesses. The respondents were predominantly of the Hausa ethnic stock (311 $(92.6 \%))$ most of these were of the Moslem faith (312(92.9\%)), (Tables 1 and 2).

Assessing the patients and their relations basic knowledge about the illness showed that only $92(27.4 \%)$ of the respondents were ever told the name of the illness they or their family member was suffering from. One hundred and ninety-nine (59.2\%) of them did not know what kind of illness they or their loved ones were suffering, $263(78.3 \%)$ were not informed about how the illness may present and 261 (77.7\%) knew nothing about the causes of the illness. The rest of the responses to the respondents' basic knowledge about their illness are shown in Table 3 below.

Knowledge about the medications the patients use for their illness was assessed and 175 (52.1\%) of the respondents knew the names of the drugs they or their relations were taking for the illness ( $(\mathrm{df} 1, \mathrm{~N}=336)$, $\left.\mathrm{X}^{2}=0.538, \mathrm{p}>0.05\right)$. A large number of the respondents $(254(75.6 \%)$, $285(84.8 \%))$ was not informed about what the drugs do or how they work respectively $\left((\mathrm{df} 1, \mathrm{~N}=336), \mathrm{X}^{2}=88.05, \mathrm{p}<0.05\right)$ and $(\mathrm{df} 1, \mathrm{~N}=336)$, $\left.\mathrm{X}^{2}=162.96, \mathrm{p}<0.05\right)$ respectively. Although a significant number of the respondents (228 (67.9\%), $\left.(\mathrm{df} 1, \mathrm{~N}=336), \mathrm{X}^{2}=42.86, \mathrm{p}<0.05\right)$ and $(151$ (44.9\%), ( $\left.\mathrm{df} 1, \mathrm{~N}=336), \mathrm{X}^{2}=3.44, \mathrm{p}>0.05\right)$ respectively) accepted being told how to take the drugs and the consequences of not adhering to medication use, only $85(25.3 \%)$ of them could mention some of the drug side effects ( $\left.(\mathrm{df} 1, \mathrm{~N}=336), \mathrm{X}^{2}=82.01, \mathrm{p}<0.05\right)$. Fifty-nine $(17.6 \%)$ of the respondents acknowledged stigma related problems of the illness, having been addressed by their health providers. Information on the ways to cope with stress associated with the illness was given to 


\begin{tabular}{|c|c|c|}
\hline No & Variable & Mean \pm SD \\
\hline 1 & Age & $37.1 \pm 13.96$ \\
\hline 2 & Duration of treatment & $6.65 \pm 5.82$ \\
\hline \multirow[t]{3}{*}{3} & Sex & Number (\%) \\
\hline & Male & $147(43.8)$ \\
\hline & Female & 189 (56.3) \\
\hline \multirow[t]{4}{*}{4} & 1. Marital status & \\
\hline & Not married & $137(40.8)$ \\
\hline & Married & $179(53.3)$ \\
\hline & Others & $20(6.0 \%)$ \\
\hline \multirow[t]{4}{*}{5} & 2. Occupation & \\
\hline & Unemployed & $195(58)$ \\
\hline & Civil Servant & $95(28.3)$ \\
\hline & Self-employed & $46(13.7)$ \\
\hline \multirow[t]{5}{*}{6} & 3. Ethnicity & \\
\hline & Hausa & 311 (92.9) \\
\hline & Yoruba & $15(4.5)$ \\
\hline & Igbo & $0(0)$ \\
\hline & Others & $10(3.0 \%)$ \\
\hline \multirow[t]{4}{*}{7} & 4. Religion & \\
\hline & Moslem & $312(92.9)$ \\
\hline & Christian & $19(5.7)$ \\
\hline & None & $5(1.5)$ \\
\hline
\end{tabular}

Table 1: The Socio-demographic characteristics of the respondents.

The predominant illness diagnosis based on the International Classification of Diseases (ICD) was schizophrenia disorder (130 (38.7\%), followed by unipolar depression $(64(19.0 \%))$. Forty-nine $(14.6 \%)$ of the respondents had bipolar affective and seizure disorders respectively.

\begin{tabular}{|c|c|c|}
\hline No & Health problem & Number (\%) \\
\hline 1 & Schizophrenia & $130(38.7)$ \\
\hline 2 & Depression(unipolar) & $64(19.0)$ \\
\hline 3 & Bipolar disorder(BAD) & $49(14.6)$ \\
\hline 4 & Anxiety disorders & $9(2.7)$ \\
\hline 5 & Autism & $8(2.4)$ \\
\hline 6 & Seizures & $49(14.6)$ \\
\hline 8 & Substance misuse & $10(3.0)$ \\
\hline 9 & Dementia & $1(0.3)$ \\
\hline
\end{tabular}

Table 2: The respondents' ICD diagnosed neuropsychiatry health problems.

\begin{tabular}{|c|c|c|c|c|c|}
\hline No & Knowledge about & Number (\%) & $\mathbf{X}^{2}$ & $\mathbf{d f}$ & $\boldsymbol{p}$-value \\
\hline 1 & Name of the illness & $92(27.4)$ & 68.76 & 1 & .000 \\
\hline 2 & Kind of illness & $137(40.8)$ & 11.44 & 1 & .000 \\
\hline 3 & What it is like to suffer illness & $73(21.7)$ & 107.44 & 1 & .000 \\
\hline 4 & How the illness presents & $73(21.7)$ & 107.44 & 1 & .000 \\
\hline 5 & How the illness presents & $75(22.3)$ & 102.96 & 1 & .000 \\
\hline 6 & What to do in an emergency situation & $51(15.2)$ & 162.96 & 1 & .000 \\
\hline
\end{tabular}

Table 3: The respondents' basic knowledge about their illness. Number (\%) number and percentage of yes responses, $\mathrm{X}^{2}=\mathrm{chi}$-square, $\mathrm{df}=$ degrees of freedom, $p$-value=level of significance.

50 (14.9\%) of the respondents and $42(12.5 \%)$ of them had structured psychotherapy sessions at any time in the course of treatment. Table 4 highlights the responses on perceived stigma and coping with the stress of illness by the respondents. In general, the responses about information to the respondents on stigma and coping with the stress of illness was statistically significant $(\mathrm{p}<0.05)$.

\section{Discussion}

This study set out to determine if the patients that attended the mental health services at the Aminu Kano Teaching Hospital routinely received psychoeducation in their course of treatment. Despite the average length of time of routine visits for treatment by the respondents at the hospital's mental health facility been about 7 years, with the Schizophrenia disorder as the predominant illness, most of the respondents had no basic knowledge of their illness. More than half knew the medications and how to take same, but the majority of them were never educated on how these drugs work, what they do to one or the likely side effects. The majority of the respondents never received any formal psychotherapy and less than one in every 5 of them was educated about the stigma associated with the illness and how to cope with the emanating stresses people with the illness go through. An earlier study by Chadzynska and Charzynska on the perspectives of patients with schizophrenia disorder who participated in psychoeducational sessions showed that although a majority (142 patients, $84 \%$ ) held a positive attitude towards the intervention, almost half of them ( 83 patients) were not satisfied with their impacted knowledge about the illness from the programme. In general, the patients felt an increase in knowledge about the illness was the most important gain from the psychoeducation. Unlike the findings from the present study, where most of the respondents had no basic knowledge about their illness, a higher proportion (79 patients, $46.7 \%$ ) of them were satisfied with the impacted knowledge about the illness from the education [12]. The above from this study indicates that most of the people with mental illness, and their families who use the Aminu Kano teaching hospital's mental health services are not empowered enough to deal optimally with the illness. The patients and their relations are not given adequate information and non-drug involved treatment measures to handle the illness. This may give rise to increased relapses and a poorer illness outcome either in the short or long term. This view is supported by the significant reduction in hospital readmissions in the Munich 2-year multicenter randomized controlled study [8]. In addition a Cochrane analysis and a study in Uganda have shown that psychoeducational interventions were accompanied by patients' higher level of compliance, lower rate of relapse, and improved psychological status [12-14]. There are noted positive impacts of mental health media enlightenment programmes as have been done even in this present area of study [15]. Presumably, some of the consumers of mental health care services in the present locale may have encountered such programmes, but the study seems to point that that may not have as much an impact as the application of such educational intervention in formal clinic settings. Despite the findings on the effectiveness of psychoeducation in the care of patients, the problem of affordability and inadequate health insurance coverage limits the beneficiaries assess to such treatment even in advanced countries as the North America [16]. This study is limited by the source of data coming from a single center, that makes generalization difficult and the non-inclusion of constructs that should have assessed the respondents' media exposure to mental health issues for evaluation. In addition, patients with some other types of psychiatric disorders, especially those with dual diagnosis, was not captured in the study sample. The study did not compare groups for correlation analysis, but this should not discredit the remarkable study findings. In conclusion the study, though simple, has surprisingly shown that clinic attenders to the mental health facilities in the present place of study were not receiving adequate psychoeducation despite the years of routine clinic visitations and this may be the case in some other underdeveloped/developing countries where adequate professional hands are lacking. There is a dare need to gather information from the mental health professionals on the problems with providing psychoeducation to the clients during formal clinic consultations in 
Citation: Takai MG, Chikaodiri AN (2015) A Descriptive Study of Clients' Perspective on Psychoeducation in a Nigerian Tertiary Hospital. J Psychiatry 18: 282 doi: 10.4172/2378-5756.1000282

Page 4 of 4

\begin{tabular}{|c|c|c|c|c|c|}
\hline No & Knowledge on stigma and coping with stress & Number (\%) & df & $\mathbf{X}^{2}$ & p-value \\
\hline 1 & Ever told how the society looks at someone with this type of illness & $59(17.6)$ & 1 & 144.44 & .000 \\
\hline 2 & Told how this can affect your mindset & $41(12.2)$ & 1 & 192.01 & .000 \\
\hline 3 & Ever taught how to think positively despite the illness & $38(11.3)$ & 1 & 201.19 & .000 \\
\hline 4 & Ever taught some healthy lifestyle behaviors with the illness & $58(17.5)$ & 1 & 144.04 & .000 \\
\hline 5 & Taught how to cope with stress related to illness & $50(14.9)$ & 1 & 165.76 & .000 \\
\hline 6 & Ever been involved in any form of psychotherapy during treatment & $42(12.5)$ & 1 & 189.00 & .000 \\
\hline
\end{tabular}

Table 4: Knowledge about the stigma and how to cope with the stress of illness by the respondents.

Number (\%) number and percentage of yes responses, $X^{2}=c h i-s q u a r e, d f=d e g r e e s$ of freedom, $p$-value=level of significance

future studies, to help in designing health care models that should properly address such problems.

\section{References}

1. Dixon $L$ (1999) Providing services to families of persons with schizophrenia: Present and future. Journal of Mental Health Policy and Economics 2: 3-8.

2. Lukens EP, Mcfarlane WR (2004) Psychoeducation as Evidence Based Practice: Considerations for Practice, Research and Policy. Brief Treatment and Crisis Intervention 4: 205-225.T

3. Colom F, Vieta E, Reinares M, Martinez-Aron A, Torrnt C, et al. (2003) Psychoeducation efficacy in bipolar disorders: beyond compliance enhancement. JCI Psychiatry 9: 1101-5.

4. Smith D, Jones I, Simpson S (2010) Psychoeducation for bipolar disorder BJPsych Advances.

5. Casanas R, Catalan R, Luis delval J, Real J, Valero S, et al. (2012) Effectiveness of a psychoeducational group program for major depression in primary care: a randomized controlled trial. BMC Psychiatry 12: 230

6. Donker T, Griffiths KM, Cuijpers P, Christensen H (2009) Psychological distress: a meta-analysis. BMC Medicine 7: 79

7. May TW, Pfafflin M (2005) Psychoeducational Programs for Patients with Epilepsy. Disease management \& Health outcomes 13: 185-199.

8. Bauml J, Frobose T, Kraumer S, Rentrop M, Pitschel-Walz G, et al. (2006) Psychoeducation: A basic Psychotherapeutic intervention for patients with schizophrenia and their families. Schizophrenia Bulletin 32: 51-59.
9. Murray-Swank AB, Dixon L (2004) Family Psychoeducation as an EvidenceBased Practice. CNS Spectr 9: 905-912.

10. http://www.psychiatrictimes.com/articles/evidence-based-practicepsychoeducation schizophrenia\#sthash.XNBIBGHM.dpuf

11. Agara AJ, Onibi OE (2007) Effects of group psychoeducation (GPE) on compliance with scheduled clinic appointments in a neuro-psychiatric hospital in southwest Nigeria: a randomized control trial (RCT). Ann Acad Med Singapore 36 : $272-5$

12. Prost E, Muisi S, Okello ES, Hopman WM (2013) The role of psycho-education in improving outcome at a general hospital psychiatric clinic in Uganda. Afr $J$ Psychiatry 16: 264-270.

13. Chadzynska M, Charzynska K (2011) The participation of patients with schizophrenia in psycho-education- the analysis from the patient's perspective. Archives of Psychiatry and Psychotherapy 2: 67-72.

14. Pekkala E, Merinder L (2011) Psychoeducation for schizophrenia. Cochrane Rev. Cochrane data base Syst Rev x 1-41

15. Wessels C, Kradenberg J, Mbanga I, Emsley RA (1999) Television as a medium for psychoeducation in South Africa: analysis of calls to a Mental Health Information Centre after screening of a TV series on psychiatric disorder Central African Journal of Medicine 45: 1-3.

16. Hogarty GE (2003) Does family psychoeducation have a future? World Psychiatry 2: 29-30. 